\title{
The effects of experimental pain and induced optimism on working memory task performance
}

Citation for published version (APA):

Boselie, J. J. L. M., Vancleef, L. M. G., \& Peters, M. L. (2016). The effects of experimental pain and induced optimism on working memory task performance. Scandinavian Journal of Pain, 12, 25-32. https://doi.org/10.1016/j.sjpain.2016.03.001

Document status and date:

Published: 01/07/2016

DOI:

10.1016/j.sjpain.2016.03.001

Document Version:

Accepted author manuscript (Peer reviewed / editorial board version)

Document license:

CC BY-NC-ND

\section{Please check the document version of this publication:}

- A submitted manuscript is the version of the article upon submission and before peer-review. There can be important differences between the submitted version and the official published version of record.

People interested in the research are advised to contact the author for the final version of the publication, or visit the DOI to the publisher's website.

- The final author version and the galley proof are versions of the publication after peer review.

- The final published version features the final layout of the paper including the volume, issue and page numbers.

Link to publication

\footnotetext{
General rights rights.

- You may freely distribute the URL identifying the publication in the public portal. please follow below link for the End User Agreement:

www.umlib.nl/taverne-license

Take down policy

If you believe that this document breaches copyright please contact us at:

repository@maastrichtuniversity.nl

providing details and we will investigate your claim.
}

Copyright and moral rights for the publications made accessible in the public portal are retained by the authors and/or other copyright owners and it is a condition of accessing publications that users recognise and abide by the legal requirements associated with these

- Users may download and print one copy of any publication from the public portal for the purpose of private study or research.

- You may not further distribute the material or use it for any profit-making activity or commercial gain

If the publication is distributed under the terms of Article $25 \mathrm{fa}$ of the Dutch Copyright Act, indicated by the "Taverne" license above, 
This work is licensed under the Creative Commons Attribution-NonCommercial-NoDerivatives 4.0 International License. To view a copy of this license, visit http://creativecommons.org/licenses/by-nc-nd/4.0/

Title

The effects of experimental pain and induced optimism on working memory task performance.

Jantine J. L. M. Boselie ${ }^{1}$

Linda M. G. Vancleef ${ }^{1}$

Madelon L. Peters ${ }^{1}$

${ }^{1}$ Clinical Psychological Science, Maastricht University, The Netherlands

Adress for correspondence:

Jantine J. L. M. Boselie

Clinical Psychological Science

Maastricht University

P.O. Box 616

6200 MD Maastricht

The Netherlands

jantine.boselie@maastrichtuniversity.nl

\section{Disclosures}

This research was funded by grant 022.003 .038 from NWO, The Netherlands Organisation for Scientific Research, awarded to the Dutch-Flemish Research School of Experimental Psychopathology. The contribution of Madelon Peters is supported by a grant (Grant number: 453-07-005 from the Netherlands Organization for Scientific Research (NWO). The contribution of Linda Vancleef is partially supported by the Netherlands Organization for Scientific Research (NWO: grant number 451-09-026). There are no financial or other relationships that might lead to a conflict of interest. 


\section{Abstract}

Background/Aims: Pain can interrupt and deteriorate executive task performance. We have previously shown that experimentally induced optimism can diminish the deteriorating effect of cold pressor pain on a subsequent working memory task (i.e. operation span task). In two successive experiments we sought further evidence for the protective role of optimism on pain-induced working memory impairments. We used another working memory task (i.e. 2-back task) that was performed either after or during pain induction.

Methods: Study 1 employed a 2 (optimism vs. no-optimism) x 2 (pain vs. no-pain) x 2 (pre-score vs. post-score) mixed factorial design. In half of the participants optimism was induced by the Best Possible Self (BPS) manipulation, which required them to write and visualize about a life in the future where everything turned out for the best. In the control condition, participants wrote and visualized a typical day in their life (TD). Next, participants completed either the cold pressor task (CPT) or a warm water control task (WWCT). Before (baseline) and after the CPT or WWCT participants working memory performance was measured with the 2back task. The 2-back task measures the ability to monitor and update working memory representation by asking participants to indicate whether the current stimulus corresponds to the stimulus that was presented 2 stimuli ago. Study 2 had a 2 (optimism vs. no-optimism) $\times 2$ (pain vs. no-pain) mixed factorial design. After receiving the BPS or control manipulation, participants completed the 2-back task twice: once with painful heat stimulation, and once without any stimulation (counter-balanced order). Continuous heat stimulation was used with temperatures oscillating around $1^{\circ} \mathrm{C}$ above and $1^{\circ} \mathrm{C}$ below the individual pain threshold.

\section{Results:}

In study 1, the results did not show an effect of cold pressor pain on subsequent 2-back task performance. Results of study 2 indicated that heat pain impaired concurrent 2-back task performance. However, no evidence was found that optimism protected against this pain-induced performance deterioration.

Conclusions: Experimentally induced pain impairs concurrent but not subsequent working memory task performance. Manipulated optimism did not counteract pain-induced deterioration of 2-back performance.

Implications: It is important to explore factors that may diminish the negative impact of pain on the ability to function in daily life, as pain itself often cannot be remediated. We are planning to conduct future studies that 
should shed further light on the conditions, contexts and executive operations for which optimism can act as a protective factor.

Key words: optimism; pain; working memory; executive functioning; deterioration.

\section{Highlights}

- Writing and visualizing about your best possible future self can increase optimism.

- Cold pressor pain did not impair subsequent working memory task performance.

- Heat pain significantly deteriorated simultaneous working memory task performance.

- Manipulated optimism did not counteract pain-induced task performance decrements.

\section{General introduction}

Persistent pain may not only lead to physical disability, but also to difficulties in executive functioning. Executive functioning, encompassing the ability to actively monitor behaviour, inhibit or facilitate certain responses, and optimise one's approach to unfamiliar circumstances, is necessary for accurate task performance ${ }^{18,30,43}$. Several studies have demonstrated that experimentally induced pain impairs concurrent ${ }^{6}$, 10-12, 31 and subsequent executive task performance ${ }^{5,41}$. Although the association between chronic pain and executive functioning deficits is less clear, there appears to be sufficient evidence that persistent pain impairs executive functioning in chronic pain patients ${ }^{3,33}$. These pain-related deteriorations have been reported on various aspects of executive functioning, including working memory performance, task switching and inhibition of dominant responses $31,33,49$.

Optimism, the tendency to expect that good things will happen in the future ${ }^{7}$, has been associated with beneficial coping strategies ${ }^{36,44}$ and applying different coping strategies more flexibly ${ }^{36,44}$. In addition, optimism has also been positively associated with greater goal attainment despite pain ${ }^{1,13}$, reduced pain intensity ${ }^{19,27}$, and better and faster recovery and less rehospitalisation after surgery ${ }^{8,23,27,39,40}$. Recently, we have demonstrated that optimism can diminish the deteriorating effect of experimentally induced pain on working memory performance ${ }^{5}$ as measured with the operation-span task. In this study, optimism was manipulated by a best possible self-manipulation (BPS) ${ }^{35}$ after which participants received either the painful 
cold pressor task or a non-painful task. Subsequent performance on the operation-span task was worse for participants in the painful cold pressor condition, but not when they had received the optimism manipulation ${ }^{5}$.

This paper describes two studies that were set up to further examine the protective effect of manipulated optimism on pain-induced working memory task performance deterioration, and to examine whether this generalizes to a different working memory task, i.e. the 2-back task ${ }^{26}$. Both the 2-back and operation-span task are considered to measure updating and monitoring of working memory representations ${ }^{30}$. In study 1, the 2-back task was administered after completion of the cold pressor test. Study 2 used concurrent heat pain stimulation during 2-back task performance. Concurrent heat pain has previously been demonstrated to impair 2-back task performance ${ }^{31,32}$. It was hypothesized that (i) pain will decrease subsequent (study 1) and concurrent (study 2) 2-back task performance and (ii) an optimism induction counteracts the deteriorating effect of pain on working memory task performance.

\section{Study 1}

\section{Methods}

\section{Participants}

A total of 81 (17 male; mean age $=21.35, S D=4.28$ ) healthy undergraduates from Maastricht University participated in this study. Exclusion criteria were suffering from a chronic pain disorder, cardiovascular disease, Reynaud disease or pain complaints at the moment of testing. This study had a 2 (optimism: optimism vs. nooptimism) x 2 (pain: pain vs. no-pain) $\times 2$ (time: pre-score vs. post-score on the 2-back task) mixed factorial design. Participants were randomly assigned to one of the four conditions: (i) optimism and pain ( $n=21,5$ male, mean age $=20.43, \mathrm{SD}=2.64)$, (ii) optimism and no-pain $(n=20,5$ male, mean age $=21.55, \mathrm{SD}=3.25)$, (iii) no-optimism and pain $(n=20,3$ male, mean age $=22.40$, SD $=7.19)$ and (iv) no-optimism and no-pain $(n=20,4$ male, mean age $=21.05, S D=2.28$ ). During recruitment, participants were informed that they would experience a procedure that could be perceived as unpleasant. Participation was rewarded with a gift voucher of 10 Euro or course credits. The local ethical committee of the Faculty of Psychology and Neuroscience, Maastricht University approved the study protocol. 
Manipulations

\section{Optimism manipulation}

Optimism was induced by the Best Possible Self (BPS) manipulation, a positive future thinking technique based on work by King ${ }^{24}$. Previous research has confirmed the effectiveness of the BPS in increasing positive affect, positive future expectancies and decreasing negative affect and negative future expectancies $5,19,35$. Participants either received the BPS manipulation, which required them to write about a life in the future where everything turned out for the best, or the neutral manipulation, which consisted of writing about a Typical Day (TD).

The instructions were as follows ${ }^{35}$ : BPS condition, “'Think about your best possible self' means that you imagine yourself in the future, after everything has gone as well as it possibly could. You have worked hard and succeeded at accomplishing all the goals of your life. Think of this as the realization of your dreams, and that you have reached your full potential."' TD condition, "'Think about your typical day' means that you take notice of ordinary details of your day that you usually don't think about. These might include particular classes or meetings you attend to, people you meet, things you do, typical thoughts you have during the day. Think of this as moving through your typical day, hour after hour."

Both manipulations followed the same procedure: 1 minute thinking about what to write followed by uninterrupted writing for 15 minutes and ending with 5 minutes of imagining the story that was just written. Instructions were given both verbally and in writing.

\section{Pain manipulation}

In the pain condition $(n=41)$ the Cold Pressor Task (CPT) was used as a painful stimulus. The water tank in which the CPT was performed consisted of a plexiglas box (JULABO Labortechnik GmbH, Seelbach, Germany) filled with water that was kept constant at $2^{\circ} \mathrm{C}$ using an electrical immersion cooler (JULABO type FT200) and a circulation pump (JULABO type ED-19). Participants were instructed to submerge their right hand as long as possible (pain tolerance) but were allowed to stop the task at any point without any consequences.

Participants in the no-pain condition $(n=40)$ followed the same procedure, with the exception that the water temperature was held constant at a comfortable $34^{\circ} \mathrm{C}$ (warm water control task; WWCT). 
Furthermore, to match immersion times of the CPT, participants were randomly requested to remove their hand from the water at 1, 2, or 3 minutes after immersion.

\section{Measures}

Working memory: 2-back task

The 2-back task is considered as a working memory task that predominantly measures the ability to monitor and update working memory representation ${ }^{20,22}$. In the 2-back task, stimuli (i.e., letters) are presented one-byone on a computer screen, and participants have to indicate for each stimulus whether this stimulus corresponds to the stimulus that was presented 2 stimuli ago. For example, when the stimuli sequence is $\mathrm{T}-\mathrm{H}$ P-J-P the participant will only respond with 'yes' to the last letter, as the letter P was also presented two letters ago. All the other letters in this example sequence have to be categorized by the participant as 'no'.

The stimuli consisted of the consonants of the alphabet, excluding the letter $x$, and were presented in randomized order. The letters were black, bold and presented in Arial with a font size of 70 . Within one trial, a single letter was presented centrally on screen for $500 \mathrm{~ms}$, followed by a blank screen for $1500 \mathrm{~ms}$. The response had to be given within these 2000 ms. The next trial (i.e. presentation of letter) started when 2000 ms (letter + blank screen) had passed. Responses were provided on a two button response box. Participants had to press the left button if the current letter was not presented two letters ago (i.e. 'no') and the right button if the current letter matched (i.e. 'yes'). The word yes and no were visually presented below the corresponding buttons on the response box. Participants were instructed, to rest their index fingers on the response buttons to ensure a fast response.

The 2-back task consisted of a practice phase and a testing phase. The practice phase consisted of 20 trials. To ensure that participants understood the task instructions, we added the possibility to repeat the practice phase. After the practice phase, an accuracy percentage was displayed centrally on the screen. If the percentage fell below $50 \%$ chance level, participants had to repeat the practice phase. When the accuracy percentage was between 50 and $65 \%$, the participant was given the choice to continue or repeat the practice phase. Participants continued immediately with the testing phase when the accuracy level was $65 \%$ or more. The testing phase of the task consisted of 90 trials, with 30 target letters (response: 'yes') and 60 non-target letters (response: 'no'). In the testing phase, we introduced a break between every block of 30 letters. The 
duration of the break was self-paced; the next block began when the participant either pressed the space bar or 'yes' on the response box.

Dependent variables in the task are hits (sum correctly identified targets), misses (sum missed targets), correct rejections (sum correctly identified non-targets), false alarms (sum non-targets identified as targets), accuracy percentage (summation hits and correct rejections percentage), and sensitivity accuracy (sum hits minus false alarms). Non-responses are not reported.

\section{Baseline questionnaires}

The Life Orientation Test-Revised (LOT-R) ${ }^{38}$ was used to assess the level of dispositional optimism. The LOT-R consists of 10 items: 3 positively phrased items (e.g., 'I'm always optimistic about my future'), 3 negatively phrased items (e.g., 'I rarely count on good things happening to me') and 4 filler items (e.g., 'It's important for me to keep busy') that are rated on a 5-point Likert scale, ranging from 1 (strongly disagree) to 5 (strongly agree). The total LOT-R score is obtained by summation of the scores on the positively phrased items and the reversed scores on the negatively phrased items and ranges from 10 to 30 . Higher scores reflect higher levels of dispositional optimism. The LOT-R has been demonstrated to be a reliable and valid measurement instrument 38

Pain Catastrophizing was measured by the Pain Catastrophizing Scale (PCS) ${ }^{46}$.Participants indicate to what degree they experienced each of 13 stated thoughts and feelings while experiencing pain on a 5- point Likert scale, ranging from 0 (not at all) to 4 (all the time). An example of an item is 'I keep thinking about how much it hurts'. The total PCS score is obtained by summing the responses of all the 13 items (scores range from 0 to 52). Higher scores on the PCS indicate greater pain catastrophizing ${ }^{34}$. The PCS has been found to be a reliable and valid measurement instrument ${ }^{34}$.

\section{Manipulation checks}

Effectiveness of the optimism induction was assessed by means of the The Future Expectancies Scale (FEX) ${ }^{19}$ and the Positive and Negative Affect Schedule (PANAS) ${ }^{50}$.

The FEX measures positive and negative future expectancies. It consists of 20 statements about positive ( $n=10$; e.g., 'people will admire you') and negative $(n=10$; e.g., 'things will not turn out as you had 
hoped") future events in 5 different domains (work, health, personal, social and general). Participants rate the likelihood that they will experience the specific events on a 7-point Likert scale, ranging from 1 (not at all likely to occur) to 7 (extremely likely to occur). Higher scores reflect a higher estimated likelihood of positive (FEXPos) or negative (FEX-Neg) future events, with scores ranging from 10 to 70 . The internal consistency of the FEX has been demonstrated to be satisfactory ${ }^{19}$.

The PANAS consists of 20 items that measure positive (PA, 10 items) and negative (NA, 10 items) affect. Participants indicate the degree to which a certain feeling is present at that moment on a 5-point Likert scale ranging from 1 (not at all) to 5 (extremely). Subscale scores can range from 10 to 50, with higher scores on NA items reflecting higher levels of emotional distress. In contrast, high PA scores correspond to experiencing more pleasurable feelings. The PANAS has been demonstrated to be valid and reliable ${ }^{9}$.

To assess whether the pain manipulation was successful, Visual Analogue Scales (VAS) were administered to measure experienced pain intensity, and fear of pain. Each VAS was anchored 0 (no pain/ fear of pain at all) to 100 (extreme pain/ fear of pain).

\section{Procedure}

Participants first received information about the CPT and WWCT procedure (i.e. whether the water temperature was $2^{\circ} \mathrm{C}$ versus $34{ }^{\circ} \mathrm{C}$, respectively) and were informed that the procedure could be perceived as painful before they signed the informed consent. Then the FEX, PANAS, LOT-R and the PCS questionnaires were administered via computer. Subsequently, participants performed the practice phase and test phase of the 2back task (baseline) followed by a second administration of the PANAS via computer. Next, participants either received the BPS manipulation (optimism) or the TD manipulation (no-optimism) followed by administration of the FEX and the PANAS. Participants were then guided to another lab room by the experimenter for the CPT or WWCT manipulation. The pain manipulation was conducted in another lab to avoid that the noise as caused by the CPT/WWCT apparatus would exert an undesired influence on working memory task performance. Participants were instructed to submerge their right hand as long as possible (pain tolerance). Unknown to the participants, the maximum immersion duration was set at 3 minutes. If the 3 minutes maximum was reached, the experimenter signalled the participant to remove the hand from the water. In the no-pain condition, participants completed the WWCT with a pre-set immersion time of 1,2 , or 3 minutes. Immediately after immersion, participants rated the pain experience on the VAS's. Next, participants performed the 2-back task for a second time (post measurement) after which they were thanked for their participation and received their 
compensation. Participants were debriefed via e-mail after study completion. In total, the duration of the experimental lab session was approximately 1 hour.

\section{Data analyses}

Data were checked for a normal distribution and reliability analyses were performed on the FEX, LOT-R, PCS and the PANAS questionnaires. One-way analyses of variances (ANOVAs) were conducted to check for baseline differences between the four conditions ((i) BPS and pain (ii) BPS and no-pain (iii) TD and pain (iv) TD and nopain) on self-reported pain catastrophizing (PCS), optimism (LOT-R, FEX), positive and negative affect (PANAS). Similarly, to check for baseline differences between conditions on 2-back outcome variables one-way ANOVAs were performed.

The effectiveness of the optimism manipulation on positive and negative affect and positive and negative future expectancies was tested with ANCOVAs with optimism condition (BPS vs TD) as between subjects factor and baseline scores of positive and negative affect (centered) and positive and negative future expectancies (centered) as covariates. The manipulation is successful when results show a significant main effect of optimism. This method of analysing is more powerful and precise than using repeated measures ANOVA in a randomized pre-post design ${ }^{48}$.

The effectiveness of the pain manipulation was tested with one-way ANCOVAs with pain condition (CPT vs WWCT) as between subject variable and experienced pain ratings (i.e., intensity, fear of pain) as dependent variables. The PCS score (centered), CPT time (centered) and sex were entered as covariates, as high scores on the PCS, duration of pain and sex may influence pain intensity reports ${ }^{14}$.

To test the hypotheses that pain deteriorates subsequent working memory task performance and optimism can counteract the negative impact of pain, $2 \times 2$ ANCOVAs with optimism and pain condition as between subject factors, 2-back performance variables (i.e., hits, misses, correct rejections, false alarms, accuracy percentage, sensitivity accuracy) as dependent variables and baseline 2-back task performance as covariates were conducted. 


\section{Results}

Baseline descriptives

The internal consistency (Cronbach's alpha) was satisfactory for all the questionnaires (range .71-.94). Although participants $(N=81)$ were randomly assigned to a condition, a one-way ANCOVA revealed a significant difference at baseline on the PCS questionnaire only $\left(F(3,77)=3.00, p=0.04, \eta p^{2}=.11\right)$. Pairwise comparisons showed that participants in the TD and CPT condition $(M=18.45, S D=6.75)$ reported significantly more pain catastrophizing than participants in the BPS and WWCT condition $(M=12.45, S D=5.09)$, with $p<.01$. Comparisons between the TD and CPT group and the other two groups were not statistically significant at $p>$ .05 (BPS and CPT $M=14.67, S D=5.15 ;$ TD and WWCT $M=14.75, S D=8.21$ ). As pain catastrophizing may influence pain intensity reports pain catastrophizing is added as a covariate to relevant subsequent analyses ${ }^{29}$. Results of the ANOVAs did not reveal baseline differences between the four conditions on the 2-back performance variables (all $p$-values $>.05$ ). We identified two participants as outliers as their scores deviated with more than 3 standard deviations from the overall mean on several 2-back performance variables, indicating a dominant response style bias (i.e. tendency to reject targets). These participants were removed from data analysis concerning working memory task performance. The remaining 79 participants (16 male) had a mean age of 21.3 years $(S D=4.33)$.

\section{Optimism manipulation check}

Corroborating earlier findings $5,19,35$ the ANCOVAs revealed a significant main effect of the optimism manipulation, controlling for the effect of baseline scores, on positive future expectancies $(F(1,78)=21.58, p<$ $\left.0.001, \eta p^{2}=.22\right)$, positive affect $\left(F\left(1,78=27.52, p<0.001, \eta p^{2}=.26\right)\right.$ and negative future expectancies $(F(1$, $\left.78)=19.12, p<0.001, n p^{2}=.20\right)$. The optimism main effect was not significant for negative affect $(F(1,78)=$ 0.82, $\left.p=0.37, n p^{2}=.01\right)$. Participants in the BPS condition $(n=41)$ scored higher on positive future expectancies $(M=56.14, S D=3.68$ vs. $M=53.43, S D=3.73)$ and positive affect $(M=33.53, S D=6.70$ vs. $M=$ 27.73, $S D=7.05)$, and scored lower on negative future expectancies $(M=25.30, S D=6.13$ vs. $M=29.14, S D=$ 5.63) than participants in the TD condition $(n=40)$. Participants did not differ on negative affect $(M=13.09, S D$ $=3.54$ vs. $M=12.58, S D=3.58$ ). 


\section{Pain manipulation check}

Supporting the effectiveness of the pain manipulation, results of the one-way ANCOVA, with PCS score, sex and CPT-time as covariates, showed a significant main effect of the pain manipulation on pain intensity $(F(1,76)=$ 268.06, $\left.p<0.001, n p^{2}=.78\right)$ and fear of pain $\left(F(1,76)=17.70, p<0.001, n p^{2}=.19\right)$. Participants in the CPT condition $(n=41)$ reported more pain intensity $(M=59.98, S D=19.11$ vs. $M=2.20, S D=6.51)$ and more fear of pain $(M=27.10, S D=24.17$ vs. $M=5.07, S D=10.34)$ than participants in the WWCT condition $(n=40)$. The CPT time covariate was found to be significant in the model with experienced pain intensity as dependent variable only, with $F(1,76)=6.58, p=0.01, n p^{2} .08$. The covariates PCS score and sex were not significant in these analyses.

\section{Working memory task performance}

First, we conducted several ANCOVAs with baseline 2-back score as covariates and 2-back performance variables as dependent variables. Estimated mean and standard deviations of scores on the 2-back task are displayed per condition in Table 1. In contrast to our first hypothesis, the results did not support a main effect of pain condition on any of the dependent variables (all $p$ values $>.54$ ). As pain did not deteriorate task performance, it was not possible to examine whether optimism can be regarded as a protective factor against pain-induced executive task deterioration. Paired t-tests showed that 2-back performance improved over time (i.e., learning effect). Results of the paired t-tests are presented in Table 2. The main analysis was repeated once again in a sample that did not include the ten participants $(n=69)$ who reached the pre-set cold pressor task maximum and thus did not reach pain tolerance. Results were similar to the results as found in the whole sample.

Table 1. Estimated mean (M) and Standard Deviation (SD) scores on the 2-back dependent variables, displayed per condition.

\begin{tabular}{lcccc}
\hline \multicolumn{2}{c}{ Best Possible Self (optimism) } & \multicolumn{2}{c}{ Typical day (no-optimism) } \\
\hline Pain condition & No-pain condition & Pain condition & No-pain condition \\
& $(n=20)$ & $(n=20)$ & $(n=19)$ & $(n=20)$ \\
$M(S D)$ & $M(S D)$ & $M(S D)$ & $M(S D)$ \\
\hline hits & & & & $26.19(5.10)$ \\
misses & $26.21(5.09)$ & $25.78(5.08)$ & $26.45(5.28)$ & $2.69(5.08)$
\end{tabular}




$\begin{array}{lcccc}\text { correct rejections } & 58.33(2.88) & 59.14(2.88) & 58.97(2.96) & 58.51(2.88) \\ \text { false alarms } & 1.18(2.18) & 0.58(2.18) & 0.62(2.23) & 0.96(2.19) \\ \text { accuracy percentage } & 93.93(6.89) & 94.36(6.85) & 94.94(7.15) & 94.12(6.87) \\ \text { sensitivity accuracy } & 24.99(5.73) & 25.21(5.71) & 25.86(5.95) & 25.19(5.76)\end{array}$

Notes: hits = sum targets; misses = sum missed targets; correct rejections = sum non-targets; false alarms = sum incorrect targets; accuracy percentage = sum hits + correct rejections; sensitivity accuracy = hits minus false alarms. Non responses are not reported.

Table 2. Results of the paired t-tests with mean (M) and standard deviation (SD) scores on the 2-back dependent variables, displayed per time-point.

\begin{tabular}{|c|c|c|c|c|c|}
\hline & $\begin{array}{c}\text { Time-point } 1 \\
M(S D)\end{array}$ & $\begin{array}{c}\text { Time-point } 2 \\
M(S D)\end{array}$ & $t$ value & Cohen's d & $\begin{array}{c}\text { 95\% Confidence } \\
\text { Interval of d }\end{array}$ \\
\hline hits & $24.06(3.66)$ & $26.15(2.95)$ & $5.72 * * *$ & 1.29 & $0.95-1.64$ \\
\hline misses & $5.76(3.56)$ & $3.75(2.88)$ & $5.51^{* * *}$ & 1.25 & $0.90-1.59$ \\
\hline correct rejections & $58.24(2.07)$ & $58.73(1.69)$ & $2.33^{*}$ & 0.53 & $0.21-0.85$ \\
\hline false alarms & $1.26(1.58)$ & $0.84(1.21)$ & $2.59 *$ & 0.59 & $0.27-0.91$ \\
\hline accuracy percentage & $91.44(4.60)$ & $94.33(3.90)$ & $5.97^{* * *}$ & 1.35 & $1.00-1.70$ \\
\hline sensitivity accuracy & $22.78(3.98)$ & $25.30(3.28)$ & $6.17^{* * *}$ & 1.40 & $1.05-1.75$ \\
\hline
\end{tabular}

Notes: hits = sum targets; misses = sum missed targets; correct rejections = sum non-targets; false alarms = sum incorrect targets; accuracy percentage = sum hits + correct rejections; sensitivity accuracy = hits minus false alarms. ${ }^{*}=P<.05 ;^{* *}=P<.01 ; * * *=P<.001$. Non responses are not reported.

\section{Discussion study 1}

In this first study, cold pressor pain did not affect subsequent 2-back task performance. Therefore we were not able to examine the protective effect of induced optimism on pain-related performance decrements. The 
absence of an effect of the pain induction on the 2-back task is in contrast to our earlier study ${ }^{5}$, in which subsequent performance on a working memory task (i.e. operation-span task) was found to be impaired after the cold pressor task. Furthermore, a number of studies have demonstrated that 2-back task performance is negatively influenced by experimentally induced pain ${ }^{31,32}$. However, these latter studies used dual-task paradigms that present painful stimuli during task performance, whereas our study delivered the pain stimulation prior to task performance. It is possible that the 2-back task may not be as sensitive to sustained pain-induced effects as the operation-span task. Nevertheless, the results of this study once again do emphasise the effectiveness of the optimism manipulation in an experimental lab setting ${ }^{5,19,35}$. Because study 1 failed to find an effect of pain on 2-back performance and this is a necessary condition to test the second hypothesis concerning the protective effect of optimism, in study 2 we used an exact replication of previous study designs ${ }^{31,32}$ that have shown pain-induced deterioration in 2-back task performance. These studies used contact heat as the pain stimulus and a within-subjects design for pain stimulation, i.e. participants completed the 2-back task twice: once without and once while experiencing painful heat stimulation. We added the optimism condition (BPS vs TD) as a between-subject factor. It was hypothesized that (i) concurrent pain impairs 2-back task performance; (ii) this pain-induced deterioration can be reduced with an optimism manipulation.

\section{Study 2}

\section{Methods}

Participants

A total of 65 healthy undergraduates from Maastricht University were recruited for this study. Due to technical difficulties during testing, 4 participants had to be excluded from data analysis. The remaining 61 participants (16 male) had a mean age of $21.84(S D=2.22)$. Exclusion criteria were suffering from a chronic pain disorder or currently experiencing pain, being pregnant, suffering from heart or vascular diseases, wearing an electronic implant, being diagnosed with a psychopathological disorder in the past three months, and taking anxiolytics or antidepressants. Study 2 had a 2 (optimism: BPS vs. TD) $\times 2$ (pain: pain vs. no-pain) mixed factorial design, with optimism as between subjects factor and pain as within subjects factor. Participants were randomly assigned to 
one of the two conditions: (i) BPS ( $n=32 ; 8$ male, mean age $=21.91, S D=2.29)$, (ii) TD ( $n=29 ; 8$ male, mean age $=21.76, S D=2.17)$. During recruitment, participants were informed that they would experience heat stimulation, which could be unpleasant. Participation was rewarded with a gift voucher of 15 Euro or course credit. The local ethical committee of the Faculty of Psychology and Neuroscience, Maastricht University approved the study protocol.

Manipulations

Optimism manipulation

The optimism manipulation was identical to the manipulation described in study 1.

\section{Pain manipulation}

The Medoc Pathway Advanced Thermal Stimulator (ATS) was used to induce painful heat stimulation via a metal plate $(3 * 3 \mathrm{~cm})$ that was attached on the inner side of the wrist of the non-dominant hand. Individual pain thresholds of participants were identified through the Medoc search protocol ${ }^{32}$. During this search protocol (i.e. calibration phase), heat stimulation started at baseline temperature of $32^{\circ} \mathrm{C}$ and participants could increase or decrease the temperature by pressing one of two buttons. Each button press would respectively increase or decrease temperature with $1.6^{\circ} \mathrm{C}$. The heat stimulation during the pain manipulation was modelled after the stimulus temperature that was selected as pain threshold in the calibration phase (up to a maximum of $48^{\circ} \mathrm{C}$; all participants with thresholds higher than this were tested at a temperature of $48^{\circ} \mathrm{C}$, thereby complying with safety protocol for heat pain stimulation). The heat stimulus started at the baseline temperature $\left(32^{\circ} \mathrm{C}\right)$ to increase at a rate of $8^{\circ} \mathrm{C} / \mathrm{s}$ to $1^{\circ} \mathrm{C}$ above the participant's subjective 'just painful' threshold, where it oscillated for 10 oscillations $1^{\circ} \mathrm{C}$ above and $1^{\circ} \mathrm{C}$ below the threshold, before returning to

baseline ${ }^{32}$. This cycle was repeated continuously until the cognitive task was completed (duration $=3$ minutes).

\section{Measures}

Working memory: 2-back task

As in Study 1, the 2-back task was used to measure working memory. However, we no longer introduced the opportunity for a self-paced break after each block of 30 trials, meaning that following a practice phase (20 
trials), a total of 90 trials were presented consecutively in the test phase ${ }^{32}$. Furthermore, as the Medoc probe for administration of the pain stimulus was attached to the participant's non-dominant wrist, participants responded with the index and middle finger of the dominant hand.

\section{Questionnaires}

Future expectancies, optimism, affect, pain ratings, and pain catastrophizing were assessed as in study 1.

\section{Procedure}

After signing the informed consent, participants completed the FEX, PANAS, LOT-R and the PCS questionnaires via computer. Next, participants completed the calibration phase with the following instructions: 'When the procedure starts, the starting temperature will not be perceived as painful. The aim is to find the moment that you perceive the temperature as just painful. In order to detect this moment, you will be able to increase and decrease the temperature in little steps by clicking on the right or left button. Please let me know when you feel you have found that moment.' When participants indicated that the temperature was 'just painful', participants had to indicate how painful the heat stimulation was on a scale of 0 (not at all painful) to 10 (extremely painful). Next, the heat stimulus was presented for $10 \mathrm{sec}$, after which participants rated the stimulus again. If participants rated the heat stimulation after $10 \mathrm{sec}$ below a 4, participants were asked again if they considered this temperature as 'just painful'. If this was not the case, participants were asked again to adjust the temperature until they identified their subjective pain threshold. Individual threshold temperatures generated from the calibration phase were then used during the pain manipulation.

After the calibration phase, participants performed the practice phase of the 2-back task. Subsequently, the PANAS and FEX (baseline) were administered via computer again as baseline measurement for the optimism manipulation check. Next, participant either received the BPS manipulation (optimism) or the TD manipulation (no-optimism). FEX and PANAS (post measurement) were administered again to check whether the manipulation was successful.

Next, the 2-back task was completed once with and once without simultaneously being exposed to the painful heat stimulation. The order was counterbalanced. The heat stimulation started immediately when the participant pressed on the 'yes' button after reading the task instructions of the 2-back task and stopped when the task was completed (duration $=3$ minutes). Only after task completion with painful heat stimulation, 
participants completed the VAS pain ratings on paper. Participants were then thanked for their participation and received their compensation. In total, the duration of the experimental lab session was approximately 1.5 hours. Participants were fully debriefed via e-mail after study completion.

\section{Data analyses}

Data were checked for a normal distribution and reliability analyses were performed on the FEX, LOT-R, PCS and the PANAS questionnaires. One-way ANOVAs were conducted to check for baseline differences between conditions (BPS vs. TD) on self-reported pain catastrophizing (PCS), optimism (LOT-R, FEX) and positive and negative affect (PANAS).

The effectiveness of the optimism manipulation on positive and negative affect and positive and negative future expectancies (post measurement) was tested with ANCOVAs with optimism condition as between subjects factor and baseline scores of positive and negative affect (centered) and positive and negative future expectancies (centered) as covariates.

Two-way (optimism condition $x$ pain) repeated measures ANOVAs with 2-back performance variables (i.e., hits, misses, correct rejections, false alarms, accuracy percentage, sensitivity accuracy) as dependent variables were conducted to test the hypotheses that pain deteriorates working memory task performance and that optimism can protect against this deterioration effect.

\section{Results}

\section{Baseline descriptives}

The internal consistency (Cronbach's alpha) was satisfactory for all the questionnaires (range .72-.88). Results of several ANOVAs with optimism as between subject's factor indicated that randomization was successful, as results did not reveal any significant differences between the BPS and TD condition at baseline (all p-values >.05). Three participants were excluded from data analysis concerning working memory, as they scored below chance level $(<50 \%)$ on baseline 2-back accuracy percentage scores or demonstrated a dominant response style bias (i.e. tendency to over identify targets), indicated by an extreme number of false alarms. The remaining 58 participants ( 16 male) had a mean age of 21.9 years $(S D=2.20)$. 


\section{Optimism manipulation check}

The ANCOVAs revealed a significant main effect of optimism condition, controlling for the effect of scores obtained before the manipulation, for positive future expectancies $\left(F(1,58)=3.95, p=0.05, \eta p^{2}=.06\right)$, positive affect $\left(F\left(1,58=5.09, p=0.03, n p^{2}=.08\right)\right.$ and negative future expectancies $(F(1,58)=5.09, p=0.03$, $\left.\eta p^{2}=.08\right)$. The optimism condition main effect was not significant for negative affect $(F(1,58)=0.04, p=0.85$, $\left.\eta p^{2}=.00\right)$. Participants in the BPS condition $(n=32)$ scored higher on positive future expectancies $(M=56.06$, $S D=4.05$ vs. $M=54.55, S D=4.25)$ and positive affect $(M=29.42, S D=5.61$ vs. $M=27.06, S D=5.90)$, and scored lower on negative future expectancies $(M=27.12, S D=4.47$ vs. $M=29.00, S D=4.70)$ than participants in the TD condition $(n=29)$. Participants did not differ on negative affect $(M=13.80, S D=2.51$ vs. $M=13.71$, $S D=2.64)$.

\section{Pain manipulation}

Individual pain threshold was identified during the calibration phase. Minimal obtained threshold temperature was $33.5{ }^{\circ} \mathrm{C}$ and maximal threshold temperature $47.0{ }^{\circ} \mathrm{C}$, with a mean of $42.78{ }^{\circ} \mathrm{C}(S D=2.95)$. The mean intensity score of the individual pain threshold during calibration was $4.06(S D=2.14)$. Following the 2-back task completion with concurrent heat stimulation, participants reported on VAS scales a mean pain intensity of $44.90(S D=23.98)$ and a mean fear of pain of $25.57(S D=25.18)$.

\section{Working memory task performance}

Mean and standard deviations scores on the 2-back variables are displayed in Table 3 . The optimism condition $x$ pain interactions were not significant (all $p$ values $>.60$ ). Similar, main effects of optimism condition were not significant (all $p$ values $>.24$ ). Results did indicate a main effect of pain on correct rejections $(F(1,56)=7.55, p=$ $\left.0.01, \eta p^{2}=.12\right)$, false alarms $\left(F(1,56)=7.92, p=0.01, \eta p^{2}=.12\right)$, accuracy percentage $(F(1,56)=8.49, p=$ $\left.0.01, \eta p^{2}=.13\right)$, sensitivity accuracy $\left(F(1,56)=8.45, p=0.01, n p^{2}=.13\right)$. Main effect of pain on hits and miss showed the same trend but did not reach significance: hits $\left(F(1,56)=3.54, p=0.07, \eta p^{2}=.06\right)$ and misses $(F$ $\left.(1,56)=3.35, p=0.07, n p^{2}=.06\right)$. These results indicate that pain deteriorated 2-back task performance. 


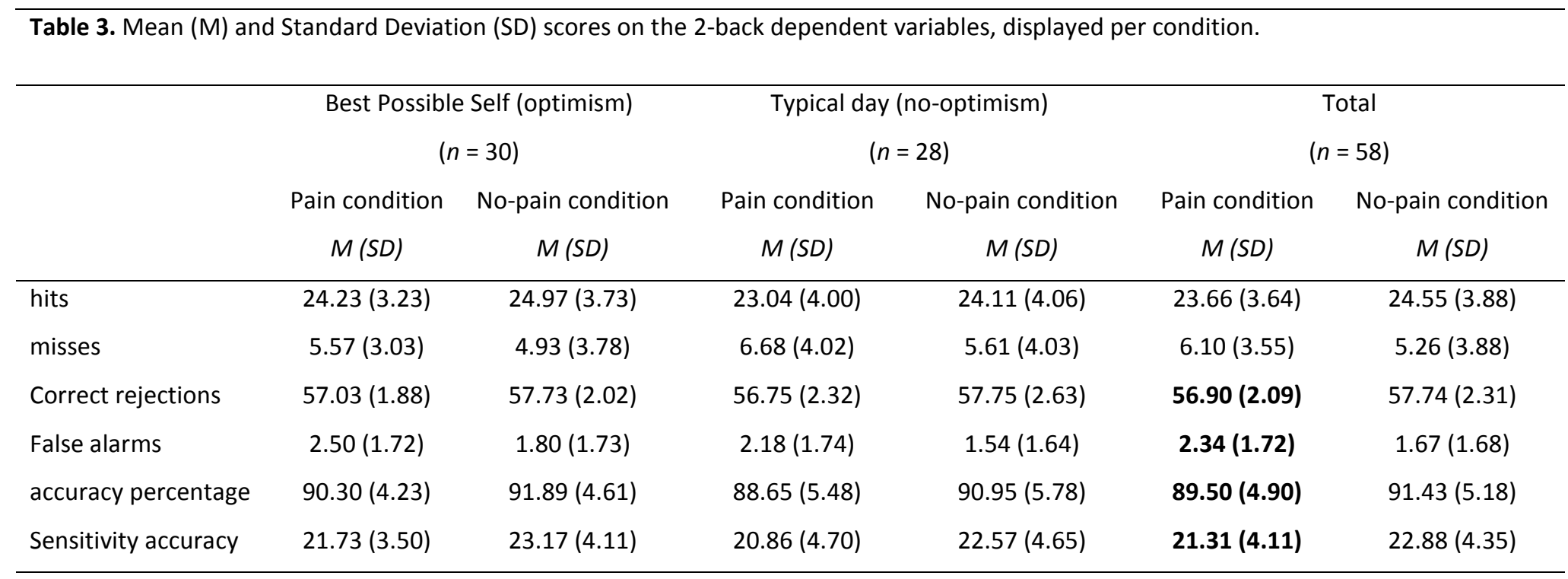

Notes: hits = sum targets; misses = sum missed targets; correct rejections = sum non-targets; false alarms = sum incorrect targets; accuracy percentage $=$ sum hits + correct rejections; sensitivity accuracy $=$ hits minus false alarms. Non responses are not reported. Bold $=p$ values $>.05$. 


\section{General discussion}

The aim of the two successive experiments was to examine whether experimental pain negatively affects subsequent or concurrent working memory task performance as measured by the 2-back task, and whether optimism can protect against this deteriorating effect. Study 1 showed that cold pressor pain did not affect subsequent 2-back task performance, however 2-back task performance was impaired when heat pain was applied during task execution (study 2). This latter finding replicates previous studies showing that concurrent heat pain impairs 2-back task performance. In fact, the pain induced task deterioration seemed more robust than previously reported, as it affected more 2-back task parameters ${ }^{31,32}$. The second hypothesis that induced optimism protects against pain-induced deterioration in task performance was not supported. We were only able to test this hypothesis in the second study where pain-induced task performance decrements were found. These decrements were comparable in the BPS and the TD condition.

Recently, experimentally induced pain was found to impair performance on a subsequent working memory task ${ }^{5}$. More specifically, participants who underwent a cold pressor task showed poorer performance on the operation-span task compared to those who were not exposed to pain. One of the aims of study 1 was to replicate this finding using a different working memory task, namely the 2-back task. This measure of working memory functioning entails both maintenance and operation of stored material. The current findings indicate that 2-back task performance was not affected by a preceding pain experience, while it was affected by concurrent pain. To our knowledge, the effects of pain on 2-back performance have previously only been tested with concurrent pain stimulation ${ }^{6,12,31,32}$. It might be suggested that the 2-back task is less sensitive for a previous pain experience compared to other working memory tasks, such as the operation-span task ${ }^{5,41}$. It should be noted that both studies used different methods to experimentally induce pain, namely cold-pressor pain versus painful heat stimulation, which arguable could also have caused the difference in results. However, the latter explanation seems less likely, since previous studies have shown that the cold pressor task is able to

induce subsequent task performance deterioration ${ }^{5,41}$. It is relevant to note that performance deterioration by the cold pressor task is also proposed to be caused by the experience of stress, with larger cortisol responses resulting in larger working memory impairments ${ }^{41}$. With the current experimental set-up in study 1 it is not possible to disentangle the influence of pain and stress. Pain research may benefit from studies that further explore stress as confounder and whether it is possible to untangle these factors. Another explanation for the 
absence of a pain effect in study 1 is the procedural format of the 2-back task. In study 1 , the 2-back task included self-paced breaks between blocks, which might have decreased task difficulty, consequently moderating the interruptive effect of pain.

In contrast to our earlier study ${ }^{5}$, the present study did not find a protective effect of induced optimism on pain-induced task performance decrements. Several explanations might be given to explain the absence of the protective effect of optimism in the present study. First, previous research has shown that optimistic individuals show more goal attainment ${ }^{7}$ and more effort to reach personal and health goals despite pain ${ }^{1,13}$. It could be reasoned that this increased goal perseverance may be the pathway by which optimism exerts its protective effect against pain-induced executive task performance deficits. But this increased goal perseverance may only be activated when the task has a particular duration. The 2-back task has a completion time of 3 minutes, whereas the operation-span task ${ }^{47}$ as used in our previous study took around 12 minutes to complete. Moreover, contrary to the 2-back task, participants in the operation-span task are required to verbally state to the experimenter whether a mathematical problem is correct, which may lead to fear of negative evaluation and stereotype threat ${ }^{28,45}$ reducing task performance. It is possible that optimism, like coping sense of humour ${ }^{17}$, buffers against the negative performance effects partly because it decreases performance anxiety and increases self-efficacy ${ }^{42}$.

Second, it is possible that optimism can only act as a protective factor, if a certain amount of executive resources are dedicated to task performance. The amount of executive resources that are given to a certain task partly depends on task difficulty and contextual factors. The operation-span task requires participants to solve arithmetic problems while simultaneously remembering and recall unrelated words in their order of presentation. The presentation sequence of trials in the operation-span were randomized, which eliminates any strategy that is built on knowledge about the amount of words that need to be remembered ${ }^{16}$. This absence of strategy may have increased task demand ${ }^{4,25,37}$, resulting that more executive resources are allocated towards this task compared to the 2-back task. Taken together, the discussion above addresses the importance of matching task characteristics when examining the generalisability of an effect.

Not only the amount of executive resources dedicated to task performance may be an important factor, but also which cognitive processes are involved. Executive functioning is an umbrella term that describes multiple cognitive processes that allows us to effortful guide our behaviour to a certain goal, especially in non-routine situations ${ }^{2,3,15}$. Although the operation-span task and the 2-back task are regarded 
both as working memory tasks that require executive functioning, the reported correlation between these tasks is low ${ }^{21}$. Furthermore, when the two tasks are used to predict performance on a general fluid intelligence measure, both explained a portion of the variances independently from each other ${ }^{20,21}$. These findings indicate that although both tasks are considered to measure executive functioning, namely updating and monitoring of working memory representations ${ }^{30}$, they in fact may measure a different construct or different parts of the same construct. Future research should attempt to gain more insight in differences and or similarities between tasks that are considered to measure executive functioning.

In summary, this study replicated previous studies showing that pain can negatively affect working memory task performance. It is important to explore factors that may diminish the negative impact of pain on executive functions, because this may have implications for people experiencing persistent pain. The ability to actively monitor behaviour, memory, and inhibiting certain responses is necessary to function in daily life, despite pain being present. In study 2, we were not able to replicate our previous finding that optimism can act as a protective factor against pain-induced deterioration in task performance. Compared to our previous study, the present study used a different executive functioning task and a different pain stimulus. We are planning to conduct future studies that should shed further light on the conditions, contexts and executive operations for which optimism can act as a protective factor.

\section{Acknowledgements}


We would like to thank Dr. David Moore and colleagues for providing us with the 2-back task ${ }^{31}$ and Katrin Blum and Nadia Hutten for their help in the data collection.

\section{Abbreviations}

- BPS: Best Possible Self manipulation

- TD: Typical Day Manipulation

- CPT: Cold Pressor Task

- WWCT: Warm water control task

- LOT-R: Life Orientation Test-Revised

- PCS: Pain Catastrophizing Scale

- FEX: Future Expectancies Scale

- FEX-Neg: Future Expectancies Scale-negative subscale

- FEX-Pos: Future Expectancies Scale-positive subscale

- PANAS: Positive and Negative Affect Schedule

- PA: Positive Affect subscale

- NA: Negative Affect subscale

- VAS: Visual Analogue Scales

- ANOVA: Analyses of variances 


\section{References}

1. Affleck G, Tennen H, Zautra A, Urrows S, Abeles M, Karoly P. Women's pursuit of personal goals in daily life with fibromyalgia: A value-expectancy analysis. Journal of Consulting and Clinical Psychology. 69:587-596, 2001

2. Banich MT. Executive function the search for an integrated account. Current Directions in Psychological Science. 18:89-94, 2009

3. Berryman C, Stanton TR, Bowering KJ, Tabor A, McFarlane A, Moseley GL. Do people with chronic pain have impaired executive function? A meta-analytical review. Clinical Psychology Review. 34:563-579, 2014

4. Bingel U, Rose M, Gläscher J, Büchel C. fMRI Reveals How Pain Modulates Visual Object Processing in the Ventral Visual Stream. Neuron. 55:157-167, 2007

5. Boselie JJ, Vancleef LM, Smeets T, Peters ML. Increasing optimism abolishes pain-induced impairments in executive task performance. Pain. 155:334-340, 2014

6. Buhle J, Wager TD. Performance-dependent inhibition of pain by an executive working memory task. Pain. 149:19-26, 2010

7. Carver CS, Scheier MF, Segerstrom SC. Optimism. Clinical Psychology Review. 30:879-889, 2010

8. Chamberlain K, Petrie K, Azariah R. The role of optimism and sense of coherence in predicting recovery following surgery. Psychology and Health. 7:301-310, 1992

9. Crawford JR, Henry JD. The Positive and Negative Affect Schedule (PANAS): Construct validity, measurement properties and normative data in a large non-clinical sample. British Journal of Clinical Psychology. 43:245-265, 2004

10. Crombez G, Eccleston C, Baeyens F, Eelen P. The disruptive nature of pain: An experimental investigation. Behaviour Research and Therapy. 34:911-918, 1996

11. Crombez G, Eccleston $C$, Baeyens F, Eelen P. Habituation and the interference of pain with task performance. Pain. 70:149-154, 1997

12. Crombez G, Eccleston C, Baeyens F, Eelen P. Attentional disruption is enhanced by the threat of pain. Behaviour Research and Therapy. 36:195-204, 1998

13. Duke J, Leventhal H, Brownlee S, Leventhal EA. Giving up and replacing activities in response to illness. The Journals of Gerontology: Series B: Psychological Sciences and Social Sciences. 57B:P367-P376, 2002

14. Ehde DM, Jensen MP: Coping and catastrophic thinking: The experience and treatment of chronic pain. In: Rational and irrational beliefs: Research, theory, and clinical practice.(David, D., Lynn, S.J., Ellis, A., Eds.), Oxford University Press, New York, NY US, 2010, pp. 265-288.

15. Elliott R. Executive functions and their disorders Imaging in clinical neuroscience. British Medical Bulletin. 65:49-59, 2003

16. Engle RW, Cantor J, Carullo JJ. Individual differences in working memory and comprehension: A test of four hypotheses. Journal of Experimental Psychology: Learning, Memory, and Cognition. 18:972-992, 1992

17. Ford TE, Ferguson MA, Brooks JL, Hagadone KM. Coping sense of humor reduces effects of stereotype threat on women's math performance. Personality and Social Psychology Bulletin. 30:643-653, 2004

18. Gilbert SJ, Burgess PW. Executive function. Current Biology. 18:R110-R114, 2008

19. Hanssen MM, Peters ML, Vlaeyen JW, Meevissen YM, Vancleef LM. Optimism lowers pain: Evidence of the causal status and underlying mechanisms. Pain. 154:53-58, 2013

20. Jaeggi SM, Buschkuehl M, Perrig WJ, Meier B. The concurrent validity of the N-back task as a working memory measure. Memory. 18:394-412, 2010

21. Kane MJ, Conway ARA, Miura TK, Colflesh GJH. Working memory, attention control, and the $\mathrm{n}$-back task: A question of construct validity. Journal of Experimental Psychology: Learning, Memory, and Cognition. 33:615-622, 2007

22. Kane MJ, Engle RW. The role of prefrontal cortex in working-memory capacity, executive attention, and general fluid intelligence: An individual-differences perspective. Psychonomic Bulletin \& Review. 9:637-671, 2002

23. King KB, Rowe MA, Kimble LP, Zerwic JJ. Optimism, coping, and long-term recovery from coronary artery surgery in women. Research in nursing \& health. 21:15-26, 1998 
24. King LA. The health benefits of writing about life goals. Personality and Social Psychology Bulletin. 27:798-807, 2001

25. Legrain V, Crombez G, Mouraux A. Controlling attention to nociceptive stimuli with working memory. 2011

26. Lezak MD, Howieson DB, Loring DW: Neuropsychological assessment, Oxford University Press, USA, 2004.

27. Mahler $\mathrm{H}$, Kulik J. Optimism, pessimism and recovery from coronary bypass surgery: Prediction of affect, pain and functional status. Psychology, health \& medicine. 5:347-358, 2000

28. Mesagno C, Harvey JT, Janelle CM. Choking under pressure: The role of fear of negative evaluation. Psychology of Sport and Exercise. 13:60-68, 2012

29. Miller GA, Chapman JP. Misunderstanding analysis of covariance. Journal of abnormal psychology. 110:40, 2001

30. Miyake A, Friedman NP, Emerson MJ, Witzki AH, Howerter A. The unity and diversity of executive functions and their contributions to complex 'frontal lobe' tasks: A latent variable analysis. Cognitive Psychology. 41:49-100, 2000

31. Moore DJ, Keogh E, Eccleston C. The interruptive effect of pain on attention. The Quarterly Journal of Experimental Psychology. 65:565-586, 2012

32. Moore DJ, Keogh E, Eccleston C. The effect of threat on attentional interruption by pain. Pain. 154:8288, 2013

33. Moriarty O, McGuire BE, Finn DP. The effect of pain on cognitive function: a review of clinical and preclinical research. Progress in Neurobiology. 93:385-404, 2011

34. Osman A, Barrios FX, Gutierrez PM, Kopper BA, Merrifield T, Grittmann L. The Pain Catastrophizing Scale: Further psychometric evaluation with adult samples. Journal of Behavioral Medicine. 23:351365, 2000

35. Peters ML, Flink IK, Boersma K, Linton SJ. Manipulating optimism: Can imagining a best possible self be used to increase positive future expectancies? The Journal of Positive Psychology. 5:204-211, 2010

36. Rasmussen HN, Wrosch C, Scheier MF, Carver CS. Self-regulation processes and health: the importance of optimism and goal adjustment. J Pers. 74:1721-1747, 2006

37. Romero YR, Straube T, Nitsch A, Miltner WH, Weiss T. Interaction between stimulus intensity and perceptual load in the attentional control of pain. Pain. 154:135-140, 2013

38. Scheier MF, Carver CS, Bridges MW. Distinguishing optimism from neuroticism (and trait anxiety, selfmastery, and self-esteem): A reevaluation of the Life Orientation Test. Journal of Personality and Social Psychology. 67:1063-1078, 1994

39. Scheier MF, Matthews KA, Owens JF, Magovern GJ, Lefebvre RC, Abbott RA, Carver CS. Dispositional optimism and recovery from coronary artery bypass surgery: the beneficial effects on physical and psychological well-being. Journal of Personality and Social Psychology. 57:1024, 1989

40. Scheier MF, Matthews KA, Owens JF, Schulz R, Bridges MW, Magovern GJ, Carver CS. Optimism and rehospitalization after coronary artery bypass graft surgery. Archives of internal medicine. 159:829835, 1999

41. Schoofs D, Wolf OT, Smeets T. Cold pressor stress impairs performance on working memory tasks requiring executive functions in healthy young men. Behavioral Neuroscience. 123:1066-1075, 2009

42. Siddique HI, LaSalle-Ricci VH, Glass CR, Arnkoff DB, Díaz RJ. Worry, optimism, and expectations as predictors of anxiety and performance in the first year of law school. Cognitive Therapy and Research. 30:667-676, 2006

43. Smith EE, Jonides J. Storage and executive processes in the frontal lobes. Science. 283:1657-1661, 1999

44. Solberg Nes L, Segerstrom SC, Sephton SE. Engagement and Arousal: Optimism's Effects During a Brief Stressor. Personality and Social Psychology Bulletin. 31:111-120, 2005

45. Steele CM, Spencer SJ, Aronson J. Contending with group image: The psychology of stereotype and social identity threat. Advances in experimental social psychology. 34:379-440, 2002

46. Sullivan MJL, Bishop SR, Pivik J. The Pain Catastrophizing Scale: Development and validation. Psychological Assessment. 7:524-532, 1995

47. Turner ML, Engle RW. Is working memory capacity task dependent? Journal of Memory and Language. 28:127-154, 1989

48. Van Breukelen GJP. ANCOVA versus change from baseline had more power in randomized studies and more bias in nonrandomized studies. Journal of Clinical Epidemiology. 59:920-925, 2006 
49. Van Ryckeghem DM, Crombez G, Eccleston C, Liefooghe B, Van Damme S. The interruptive effect of pain in a multitask environment: an experimental investigation. The Journal of Pain. 13:131-138, 2012

50. Watson D, Clark LA, Tellegen A. Development and validation of brief measures of positive and negative affect: The PANAS scales. Journal of Personality and Social Psychology. 54:1063-1070, 1988 